\section{THE NATURAL HISTORY OF CANADA}

R.D. LAWRENCE. 1988. Key Porter Books, Toronto. 304 pp., illus. colour and $\mathrm{b} / \mathrm{w}$, maps, charts, cloth $\$ 39.95$.

This is a general natural history of Canada written for the layman. In the preface, Lawrence takes care to explain the connection between his philosophy and the style of this book. That connection is important to our understanding of his aim:

Soon after completing four years of biological studies, during which I majored in mammalogy, I found myself frustrated by the restrictive foci of the science and especially by the fact that my tutors sought to push me towards a cloistered specialty. I wanted to be a generalist; I wanted to study life in the field ... So I turned to writing...dedicating myself to field study and later interpreting my findings in language understandable to the layman. I feel that it is vital to the well-being of the world to simplify biology for those who need, and want, to be informed, but who cannot grasp the meanings concealed in the jargon-ridden scientific texts and papers.

Of the 17 ecosystems presently recognized in Canada, this book devotes a chapter to each of the 11 vegetation zones, with the shoreline and marine environments being briefly covered in the introduction and in the chapter headed Water and Life. This arrangement, although simplified, works well, and the author gives a picture of each biome and its surrounding zones without overwhelming us with details. A good portrait of the nature of Canada is presented, in keeping with Lawrence's stated intention.

And just imagine - here is a book about Canada that does not first focus on the "East"! This one fittingly begins with the Ice Ages and the Tropical Arctic, since there was the genesis of the Canada we know today. Then it moves south to the tundra and the other biomes: northern transition, boreal, coast, subalpine, alpine, montane, Columbia, grasslands, Great Lakes-St. Lawrence, deciduous and Acadian. There is some discrepancy between the list of biomes given on the map and those in the text, but it only serves to accent the difficulty of classifying rather amorphous natural zones.

The 160 photographs serve to highlight the plants, animals and relationships making up a biome which are spoken of in the text. Most of the pictures are very good; one has been incorrectly captioned: Snow Geese winging across the sky have become Canadas by the time you read the caption. I would rather have seen photo credits with each photo, instead of at the end of the book. The line drawings and silhouettes are not well done; the pastel plates are a bit better, but note that they are not to scale.

However, small faults such as these do not spoil an informative and wellwritten book. Adults and children alike will be able to enjoy and be motivated by it. Lawrence, in a thoughtful afterword, urges conservationists of every stripe, facing the spectre of environmental destruction on every hand, to speak with one voice if they expect to be heard and heeded. He exhorts us to remember that

We humans are natural organisms; if we reject our biological heritage (and the fundamental laws of nature that govern our bodies and a large part of our minds), we do so at our peril and without regard for future generations of our own kind or for the health of our world and its nature.

- Reviewed by Carol Bjorklund, 3634 McCallum Avenue, Regina, Saskatchewan. S4S 0S5 